\title{
A performance filosófica na escrita de Franz Kafka
}

\author{
PABLO BAPTISTA RODRIGUES *
}

* Mestrando do PPG-Ciência da Literatura da UFRJ Bolsista CNPq
RESUMO É possível que o nosso tempo assuma mais facilmente o rico diálogo entre a Filosofia e a Literatura. A relação histórica desses dois saberes, que remontam a Platão, foi tratada de maneira singular, seja pelo discípulo de Sócrates, seja por seus comentadores, apoiados no discurso filosofia versus poesia que se estabeleceu em nossa tradição filosófica. Porém, vemos que na contemporaneidade nos interessa muito mais uma aproximação filosófico-literária que se debruce sobre a linguagem e o mundo como temática do indizível, em lugar das dicotomias sensível-inteligível, mentira-verdade, metáfora-conceito, como bem expressou a professora e filósofa Jeanne Marie Gagnebin. Buscaremos em nosso trabalho observar o texto kafkiano como forma singular de aproximar Filosofia e Literatura. Se o lugar do romance para pensar a Literatura e a Teoria literária está mais do que consagrado, cabe nos agora perguntar o que em Franz Kafka nos desperta o questionamento ao filosofar. Observaremos o método kafkiano para problematizar a literatura e a tradição literária, bem como a própria Filosofia. Tendo como premissa que é por meio da inversão das categorias do conhecimento estabelecido, que Kafka trabalha sua Literatura e nos auxilia a perceber a conexão do literário com o filosófico.

PALAVRAS-chave Literatura; Filosofia; Franz Kafka. 


\section{ENTRE A LITERATURA E A FILOSOFIA}

Este texto só é possível por alguns motivos, do quais, apresento dois. A primeira motivação consiste em assumir o trabalho da escrita de um artigo como algo que se escreve como rasura, tendo como recurso uma escrita mais ensaística. E uma segunda motivação diz respeito à compreensão contemporânea de realizarmos o diálogo entre os saberes da Filosofia e Literatura de modo mais claro e possível.

Organizo este texto da seguinte forma: Tenta-se aqui expressar a possibilidade do diálogo da Filosofia com a Literatura. Entendendo, que é por meio da crítica e inversão das categorias que se faz Filosofia. Ou seja, é no "virar das mesas", no subverter o senso comum; na crítica aos padrões e normas estabelecidos. Possibilitando por meio dessas ações as reinterpretações da forma como vivemos. Em um segundo momento procurou-se demonstrar como Franz Kafka subverte o que entendemos como Literatura, para assim explicitar o caráter profundamente filosófico de seu texto. E compreender como esse método da inversão kafkiana pode ser lido como um "método filosófico" subvertendo o próprio discurso da Filosofia.

Sabemos que as relações entre a Filosofia e a Literatura nunca foram fáceis. Isso porque, muitas vezes se esqueceu do caráter intrínseco do próprio fazer filosófico. Essa afirmação é depreendida a partir da conferência realizada no II Seminário do Programa de Pós-Graduação em Literatura Brasileira da Universidade de São Paulo (2016), pela filósofa Jeanne Marie Gagnebin. A filósofa afirma:

a filosofia se autodefine e é definida de diversas maneiras segundo os momentos de sua história, segundo os momentos da história: na Idade Média, tinha que se confrontar principalmente com a teologia, por exemplo, na modernidade, desde Descartes, com as matemáticas e com as ciências exatas, hoje com outras ciências ditas humanas ou naturais. a segunda coisa é que a filosofia só pode se dar na e pela linguagem, por isso a chamei de linguística ou de linguageira ("sprachlich"), ela não trabalha primeiramente com "ideias", mas sim com palavras. História e Linguagem, inseparáveis, delimitam o exercício filosófico, 
fazendo sua grandeza e sua fragilidade - e tecendo seu parentesco com aquilo que, a partir do Romantismo alemão, costumamos chamar de "literatura". ${ }^{1}$

É de se considerar dois pontos importantes ao longo desse primeiro trecho de Gagnebin. Diante da História da Filosofia, devemos recordar as inúmeras mutações do campo filosófico. E que sem a linguagem não teríamos o "filosofar"; isso porque a Filosofia se dá na linguagem e pela linguagem. Portanto, podemos assumir que há entre Filosofia e Literatura uma intersecção e não ilhas incomunicáveis. Filosofia e Literatura surgem de um único terreno que é o solo da linguagem. O filósofo não trabalha primeiramente com ideias, mas sim com palavras. E assim, para compreender o exercício de se fazer Filosofia, é necessário compreender o lugar inseparável da Filosofia e da Literatura.

Seguindo dois dos passos de Gagnebin, vamos então contextualizar o lugar da Filosofia e Literatura que desejamos aqui estabelecer. No primeiro plano teremos a retomada da problemática em Platão e a linguagem literária como imaginação, ou em termos platônicos, a linguagem literária como mentira. O filósofo, representante da Filosofia, é o único capaz de encontrar conceitos filosóficos nas formas narrativas. Sem nos esquecermos, evidentemente, que assumimos essa primeira premissa com todo cuidado, para não reforçarmos a antiga e já superado oposição desses dois saberes. Sem as ressalvas, estaríamos louvando uma forma de linguagem, a filosófica, em detrimento da forma literária.

Se olharmos novamente para a história da filosofia, poderemos perceber o quanto a divisão platônica do mundo, em inteligível e sensível, não é tão radical como nos foi apresentada. Platão não se furta de construções literárias para os seus diálogos, utilizando mitos, metáforas para assim ajudar seus interlocutores. É na tentativa definir o trabalho de Sócrates frente ao dos sofistas que temos uma separação mais acentuada entre o logos como Filosofia, e o lugar da poesia e a retórica. Condena-se, portanto, o discurso que se sustenta no sensível, e que pretende ser autossustentado e autossuficiente.

1 GAGNEBIN, Revista Limiar, 2016, p. 5-6. 
Retornando ao livro "X” da República, de Platão lemos as seguintes afirmações:

- A verdade é que - continuei - entre muitas razões que tenho para pensar que estivemos criando uma cidade mais perfeita do que tudo, não é das menores a nossa doutrina sobre poesia.

- Que doutrina?

- A de não aceitar a parte da poesia de caráter mimético. A necessidade de a recusar em absoluto é agora, segundo me parece, ainda mais claramente evidente, desde que definimos em separado cada uma das partes da alma. ${ }^{2}$

Estamos diante da preocupação de Platão na construção da cidade ideal. Novamente cito Gagnebin em sua análise do pensamento platônico que é extremamente elucidativa:

que a sedução da beleza tenha mais força que a procura, muitas vezes difícil, ingrata, aporética, do verdadeiro. Esse perigo se concretiza nas manipulações dos demagogos (literalmente: aqueles que querem agradar ao povo em vez de educá-lo) na assembleia decisória da cidade e no ensino dos Sofistas que, segundo Platão/Sócrates, ajuda a solapar as antigas virtudes cívicas por argumentos retóricos tão brilhantes quanto vazios. ${ }^{3}$

Pois o filósofo sabia que a "mimeses artística no comove mais que o verdadeiro, a imagem mais que "realidade". ${ }^{4}$ E no planejamento da "cidade mais perfeita do que tudo", deve se levar em consideração a “doutrina sobre a poesia”, compreendendo nesse momento, a mímesis como aquilo que não é verdadeiro. Logo, não merece estar na cidade ideal. E para seguir nessa linha argumentativa vale recordar ainda da condenação da própria escrita para Platão, questão presente em seu diálogo Fedro ou da Beleza. Sócrates em diálogo com Fedro afirma que

O maior inconveniente da escrita parece-se, caro Fedro, se bem julgo, com a pintura. As figuras pintadas têm atitudes de seres vivos mas, se alguém as interrogar, manter-se-ão silenciosas, o mesmo acontecendo com os discursos: falam das coisas como se estas estivessem vivas, mas, se alguém os interroga, no intuito de obter um esclarecimento, limitam-se a repetir sempre a mesma coisa. Mais: uma vez escrito, um discurso chega a toda a parte, tanto aos que o

2 PLATÃO, A república, 2011. p. 293.

3 GAGNEBIN, Revista Limiar, 2016, p. 7-8.

4 GAGNEBIN, Revista Limiar, 2016, p. 8. 
entendem como aos que não podem compreendê-lo e, assim, nunca se chega a saber a quem serve e a quem não serve. Quando é menoscabado, ou justamente censurado, tem sempre necessidade da ajuda do seu autor, pois não é capaz de se defender nem de se proteger a si mesmo. 5

Isso porque, estando morta a pintura, ela não reponde quando interrogada. Paralelamente, a escrita também está morta não nos dizendo nada quando questionada; é, portanto, representação da ausência, e metonímia da morte e dos mortos. O que nos diria então, os limites da linguagem literária? Não nos é possível sair da linguagem para dizer sobre o mundo, sendo a relação "mundo" e "real” sempre enigmática.

E ainda que nossa argumentação passe pela tradicional oposição "mundo das ideias" e “imitação”, deve-se se lembrar do apreço de Platão a Homero, também escrito, n’A República: "É necessário que eu diga - confessei. - No entanto o respeito e admiração que nutro por Homero desde a minha infância”. ${ }^{6}$

Como pode ser pensada as questões entre os discursos filosóficos e literários quando estamos se lê argumentos contrários a própria aproximação da Filosofia e da Literatura? É Emmanuel Carneiro Leão, em seu texto Aristóteles e as questões da arte, que romperá por meio de estagirita uma tradição de leitura truncada do texto do discípulo de Sócrates: "Por isso, traduzir por copiar ou entender imitar no sentido comum em que se diz imitar como copiar não se chega nem perto do que é a experiência de arte, proposta por Aristóteles. [...] Por isso, a imitação da Arte é para Aristóteles uma criação, dádiva da realidade de um novo modo de realidade do real”. ${ }^{7}$

\section{PENSAR COM FRANZ KAFKA}

Otavio Paz em O arco e a lira tece um breve comentário sobre a obra de Miguel de Cervantes. Afirma que com Dom Quixote temos a ruptura da analogia, presente n'A divina comédia, de Dante, e o começo da subjetividade. O que o homem moderno quixotesco realizou foi o de desalojar a divindade e se deparar com a não significação do mundo. O personagem Dom Quixote se vê diante de um mundo em que as palavras não se re-

5 PLATÃO, Fedro ou da Beleza, 1994, p. 122-123.

6 PLATÃO, A república, 2011. p. 293.

7 LEÃO, “Aristóteles e as questões da arte”. CASTRO, A arte em questão: as questões da arte, 2005 , p. 116-118. 
lacionam com as coisas, isto é, um tempo de “dupla imperfeição", pois a palavra não representando a coisa, faz com que o mundo se torne embaçado.

A história do século XVI se faz em historicizar a negação do mundo europeu diante do descobrimento do Novo Mundo. Em resumo Otavio Paz define o início da Idade Moderna formadas pelas inúmeras façanhas da subjetividade ou a utilização da negação para conquista do mundo. O que para o poeta e crítico tal interpretação caberia muito bem para um terceiro romance de cavalaria aos moldes de Cervantes.

Ou será o contrário: a loucura é do mundo e dom Quixote é a palavra racional que percorre os caminhos, disfarçados de loucura? Cervantes sorri e se cala: ironia e desengano.

A ruptura da analogia é o começo da subjetividade. O homem entra em cena, desaloja a divindade e se depara com a não significação do mundo. Dupla imperfeição: as palavras deixaram de apresentar a verdadeira realidade das coisas; e as coisas se tornaram opacas, mudas. O homem tem de enfrentar uma realidade fechada em si mesma, incomunicada e incomunicável. [...] A alternativa se apresentou assim: dom Quixote não está louco: condenação do mundo, mas em nome de que princípio ou de que realidade natural sobrenatural? [...] Expulsando dom Quixote, paradigma da linguagem como irrealidade, desterrou-se o que denominamos imaginação, poesia, palavra sagrada, voz do outro mundo" 8

Em resumo, é responder à equação levantada sobre a loucura ou a sanidade de Quixote, e assumir que "a linguagem do fidalgo é desvario", e com isso, expulsar Dom Quixote e salvar o mundo. Pois não é possível tolerar que o amigo inseparável de Sancho Pança está em sanidade plena, pois assim o mundo estaria louco. Escolhido, portanto, a loucura do fidalgo, o que restou foi curá-lo e trazê-lo de volta à realidade de Alonso Quijano.

Com as considerações de Otavio Paz, podemos entrar no texto de Franz Kafka, por buscando a compreensão sobre seu fazer literário. Comecemos com este pequeno texto que se coloca na esteira da tradição literária ao reler a grande obra de Miguel de Cervantes, “A verdade sobre Sancho Pança”. Cito o texto:

8 PAZ, O arco e a lira, 2012. p. 331-332 
Sancho Pança, que por sinal nunca se vangloriou disso, no curso dos anos conseguiu, oferecendo-lhe inúmeros romances de cavalaria e de salteadores nas horas do anoitecer e da noite, afastar de si o seu demônio - a quem mais tarde deu o nome de D. Quixote - de tal maneira que este, fora de controle, realizou os atos mais loucos, os quais, no entanto, por falta de um objeto predeterminado - que deveria ser precisamente Sancho Pança -, não prejudicaram ninguém. Sancho Pança, um homem livre, acompanhou imperturbável, talvez por um certo senso de responsabilidade, D. Quixote nas suas sortidas, retirando delas um grande e proveitoso divertimento até o fim de seus dias. ${ }^{9}$

O autor d'A metamorfose inverte a posição de Dom Quixote, como pode ser lido no texto acima citado, fazendo com o que o personagem central seja a forma com que Pança “afaste de si” os seus próprios demônios. Sendo assim, os atos do fidalgo Quixote é a realização dos atos mais descontrolados, logo, os mais loucos, "que deveria ser precisamente Sancho Pança”. Quixote passa a ser a projeção de Pança. "Sancho Pança, um homem livre, acompanhou imperturbável, talvez por um certo senso de responsabilidade, D. Quixote nas suas sortidas, retirando delas um grande e proveitoso divertimento até o fim de seus dias". ${ }^{10}$

\section{TRANSFORMAR A LITERATURA E FILOSOFIA POR MEIO DOS ESCRITOS DE KAFKA}

Como pode ser lido acima, Kafka inverte a tradição moderna ao resgatar, não no sentido meramente salvífico, Dom Quixote-Sancho Pança escolhendo tornar verdade os atos do fidalgo-escudeiro. Busca-se salvar Dom Quixote, condena-se agora o mundo dos homens. O que antes foi preterido, isto é, Quixote como paradigma da linguagem desterrada da imaginação, poesia e da palavra sagrada, agora podem ser plenamente recuperados. Após compreendida essa inversão literária de Kafka, pode ser cogitado as formas como o autor pode inverter os caminhos para se fazer a própria Filosofia. Um dos importantes leitores de Franz Kafka, Günter Anders, afirma:

Aqui entramos em Kafka. A fisionomia do mundo kafkiano parece desloucada. Mas Kafka deslouca a aparência aparentemente normal do nosso mundo louco, para tornar visível sua loucura. Manipula, contudo, essa aparência louca como

9 KAFKA, Narrativas do espólio, 2012, p. 71.

10 KAFKA, Narrativas do espólio, 2012, p. 71. 
algo muito normal e, com isso, descreve até mesmo o fato louco de que o mundo louco seja considerado normal. ${ }^{11}$

A já citada obra A metamorfose é exemplo fidedigno das afirmações de Anders. Isso porque, como bem sabemos, Gregor Samsa ao acordar metamorfoseado em um inseto monstruoso se vê preocupado com suas obrigações de cacheiro viajante e enquanto membro de um família.

A metamorfose em si não é de se espantar. Sabemos dos animais falantes, das fábulas de Esopo, La Fontaine, e Monteiro Lobato. E das histórias de metamorfoses de sapos em príncipes, que servem para provar o amor e devoção de uma certa princesa. Entretanto, a metamorfose de Kafka é abrupta, e sem notícia de redenção. Nos espanta que o jovem Samsa não se preocupa com sua condição de homem-inseto, mas sim de provedor da família.

Os exemplos são inúmeros dentro da literatura de Kafka: O desaparecido ou Amerika, A pequena fábula, O castelo... Porém, buscou-se aqui outro movimento. Pensar não apenas um conceito presente nos estudos filosóficos, e aproximá-los, mas observar o quão filosófico é o texto literário. A partir da literatura kafkiana, compreender como o autor tcheco subverte não apenas o tecido literário, mas também noções da própria filosofia. Para tais exemplificações, é de interesse observar a inversões kafkianas quando aproximadas do conceito de liberdade, política e submissão.

Hannah Arendt em Entre o passado e o futuro afirma que a política e liberdade se estabelecem mutuamente. Para a formação de sua definição de liberdade a autora parte pela história da filosofia ocidental, que se inicia na Antiguidade grega, passa pela Idade Média de Santo Agostinho, até o filosofo alemão Immanuel Kant. O ser livre é o homem grego da pólis, o que tem relações entre si em liberdade. São os que usufruem em não ser dominado, também em não dominar. Uma certa isonomia ou o mover-se entre os seus iguais.

A autora pensando a partir de Santo Agostinho dirá que homem se fundamentará ontologicamente, dizendo ser ele mesmo a liberdade por meio de um começo dado pelo nascimento. (O que na filosofia de liberdade de Kant é a ideia de espontaneidade do homem). A liberdade, então, pode ser percebida na possibilidade de cada vida que 
nasce, pois habita no ser humano a potência de novos futuros. Citando Arendt: “A cada nascimento, um novo começo surge para o mundo, um novo mundo em potencial passa a existir". ${ }^{12}$

Vale ressaltar que não nos é importante a definição formal de liberdade, e nos encontramos em um dilema teórico, pois a própria Hannah Arendt formulou indiretamente o que é ato de liberdade frente ao totalitarismo. O que podemos afirmar com certeza é a necessidade do espaço público para a existência da política, e assim para a existência da liberdade. Esboça-se então, que nesse espaço de liberdade criativa, e política, residiria, portanto, a melhor forma de expressar nossa capacidade de inventarmos nossa condição de sermos livres.

É inegável o trabalho de criação de novos mundos realizados por Kafka. Não no que tange a própria revolução literária que o autor propõe, mas a possibilidade de pensar por meio do áspero novas formas de liberdade. O que espanta em Franz Kafka ao se pensar a liberdade é que se pode realizar esse questionamento tratando do conceito de submissão. Anders afirma:

É claro que não se pode imaginar o rebatismo kafkiano como um ato sempre consciente de tradução; suas re-nomeações têm pouco em comum com as das Cartas persas ou com as das Viagens de Gulliver: a visada “alienante” é, por assim dizer natural para ele. O objeto $a$, em Kafka, já na primeira apreensão, vai-se chamar $b .{ }^{13}$

Paralelamente, poderíamos assumir que o conceito $a$, liberdade, seria em Kafka, o conceito $b$, submissão. Percebe-se que a inversão aproxima dois conceitos implodindo uma certa oposição. Liberdade e submissão seriam faces de uma mesma moeda do viver. Até este ponto, estamos de acordo até mesmo, com nossa experiência diária. Porém, ao olharmos para os personagens de Kafka, percebemos que muito da resistência criada e vivida pela galeria kafkiana se dá por meio de um gesto de submissão.

A fragilidade de seus personagens, Josef K., Gregor Samsa, o oficial da Colônia Penal, o camundongo da pequena fábula, não devem ser tomados como mera entrega diante de um mundo de caos absoluto, e sim como uma forma nova de resistência. O fim de

12 ARENDT, Origens do totalitarismo, 2013, p. 498.

13 ANDERS, Kafka: pró \& contra, 2007. p. 17. 
cada um desses personagens é o fim trágico. Eles aprendem pelo sofrer. Assumir essa leitura é delicada porque nos leva a ler Franz Kafka por uma perspectiva fatalista. E o trabalho de Michel Löwy é importante para desmistificar tal leitura:

Kafka foi acusado com frequência - por George Lukács, Günther Anders e outros - de pregar, pelo seu pessimismo radical, o fatalismo e a resignação. Ora, numa cara ao seu amigo Oskar Pollak de 27 de janeiro de 1904, ele explicava assim sua concepção do papel da literatura: um livro somente tem interesse, escrevia ele, quando é "um soco no crânio que nos desperta [...], uma machadinha que rompe em nós o mar de gelo”. Isso não parece muito apela à resignação. ${ }^{14}$

Desse modo, Löwy aproxima Kafka de uma escrita "libertária”, uma busca constante de um fio vermelho. Uma espécie de socialismo libertário. Lemos então, a morte de Gregor Samsa não como a vitória da família frente ao filho; ou do seu chefe frente o trabalhador. A resposta possível está em assumir a metamorfose como uma forma de combate frente à opressão de categorias de extrema importância para Kafka, como a família, a burocracia e o Estado. Da mesma forma, ainda que seja impossível a vitória frente aos tribunais Josef $\mathrm{K}$. mergulha em seu processo.

Franz Kafka retira o véu do direito positivo colocando em questão o seu mundo abstrato. Expõe a crise de nosso sistema colocando o sangue no mundo de papel dos seus personagens como forma combativa. Como diz Hannah Arendt sobre Kafka:

Um dos principais temas nas histórias de Kafka é a construção dessa máquina, a descrição de seu funcionamento e das tentativas dos protagonistas de destruí-las na defesa das simples virtudes humanas. Esses heróis anônimos não são pessoas comuns que encontraríamos na rua, mas formam o modelo do "homem comum" como um ideal de humanidade; assim, são concebidos com a intenção de prescrever uma norma para a sociedade. Tal como o "homem esquecido" dos filmes de Chaplin, o "homem comum" de Kafka foi esquecido por uma sociedade que se divide entre humildades e figurões. Pois o motor de suas atividades é a boa vontade, contrastando com o motor da sociedade à qual ele não se ajusta, que é a funcionalidade. Essa boa vontade, que o herói encarna apenas como um modelo, também tem uma função; de maneira quase inocente, ela desmascara as estruturas ocultas da sociedade, que frustra as necessidades mais banais e destrói as mais elevadas intenções do homem. Revela as falhas de construção

14 LÖWY, Kafka: sonhador insubmisso, 2005. p. 15. 
de um mundo onde o homem de boa vontade que não quer fazer carreira está pura e simplesmente perdido ${ }^{15}$.

Novamente devemos lembrar da obra A metamorfose. O fim da novela é a morte de seu protagonista inseto, que resulta na família um certo alívio. O Gregor Samsa metamorfoseado em inseto monstruoso é jogado pela emprega dos Samsa na lixeira. Seria a vitória do mundo familiar frente ao desejo de nosso personagem? Deve-se assumir outra leitura. Quem vence é o nosso herói, porém, mais do que apontar perdedores e vencidos, pode ser assumir que a possibilidade de vencer o peso familiar está na metamorfose. Parece-nos que a solução é um devir inseto; uma submissão que oferece liberdade e dinamita as instancias familiar, burocrática e estatal.

É preciso recordar o diálogo de Franz Kafka com Max Brod, citado por Walter Benjamin em "Franz Kafka - A propósito do décimo aniversário de sua morte": "Existiria então esperanças, fora desse mundo de aparências que conhecemos? Ele [Franz Kafka] riu: há esperança suficiente, esperança infinita - mas não para nós”. ${ }^{16}$ Desmembrando a sentença kafkiana percebemos a afirmação da existência da esperança. A esperança é "suficiente" e "infinita”. No sentido mais comum seria afirmar que o ser esperançoso é o ser que tem a emoção do "sentimento de quem vê como possível a realização daquilo que se deseja; confiança em coisa boa; fé”. ${ }^{17}$ Ao seguirmos as pistas dessa definição de uso corrente chegamos a uma crítica mais profunda lançada pelo nosso autor: a esperança como uma das emoções humanas e uma das virtudes teologais, ao lado da fé e da caridade.

Essa breve noção da esperança possibilita ao leitor a seguinte compreensão: para Kafka não significa apenas negar o lugar da existência da esperança como emoção norteadora das relações humanas, mas reivindicar outras leituras. Seria mais correto ao se tratar de Kafka, que o desejo é o da “inversão radical”, daquilo que se configura como esperança no imaginário do homem moderno. Seja a espera como emoção, seja virtude, ela não existe como possibilidade para nós. Em seu sentido abstrato é possível ao homem, porém distante em seu sentido prático. Uma aporia? Franz Kafka em

15 ARENDT, Compreender: formação, exílio e totalitarismo, 2008. p. 103.

16 BENJAMIN, Obras escolhidas: magia, técnica e política, 1985, p. 142.

17 HOUAISS ELETRÔNICO, 2009. 
um dos seus aforismos: “A verdade é indivisível, portanto não pode ter conhecimento de si mesma; quem quer que diga conhece-la está se referindo a uma mentira”. ${ }^{18}$

\section{REFERÊNCIAS BIBLIOGRÁFICAS}

ANDERS, G. Kafka: pró \& contra. Tradução de Modesto Carone. São Paulo: CosacNaify, 2007.

ARENDT, H. O que é política. Rio de Janeiro: Bertrand Brasil, 2007.

ARENDT, H. Compreender: formação, exílio e totalitarismo. Tradução de Denise Bottmann. São Paulo, Belo Horizonte: Companhia das Letras, EditoraUFMG, 2008.

ARENDT, H. Origens do totalitarismo. Tradução de Roberto Raposo. São Paulo: Companhia de Bolso, 2013.

ARENDT, H. Entre o Passado e o Futuro. São Paulo: Perspectiva, 2016.

BENJAMIN, W. “Franz Kafka - A propósito do décimo aniversário de sua morte”. In: . Magia e técnica, arte e política. São Paulo: Brasiliense, 1985. p. 141-142.

BOÉTIE, É. D. L. Discurso da servidão voluntária. Tradução de Casemiro Linarth. São Paulo: Martin Claret, 2009.

CASTRO, M. A. D. A arte em questão: as questões da arte. Rio de Janeiro : 7 Letras, 2005.

GAGNEBIN, J. M. Filosofia e literatura. Limiar, São Paulo, v.3, n. 5, 2016. Disponivel em: <http://www2.unifesp.br/revistas/limiar/pdf-nr5/o1_Gagnebin-Jeanne-Marie_Filosofia-e-literatura_Limiar_vol-3_nr-5_1-sem-2016.pdf $>$.

HOUAISS Eletrônico. [S.1.]: [s.n.], 2009.

KAFKA, F. América. Tradução de Torrieri Guimarães. São Paulo: Exposição do Livro, 1965 .

KAFKA, F. Um médico rural. Tradução de Modesto Carone. São Paulo: Companhia das Letras, 1999.

18 KAFKA, Essencial: Franz Kafka, 2011, p. 201. 
KAFKA, F. O processo. Tradução de Modesto Carone. São Paulo; Rio de Janeiro: Folha de São Paulo; O Globo, 2003.

KAFKA, F. Essencial: Franz Kafka. Tradução de Modesto Carone. São Paulo: Companhia Digital, 2011.

KAFKA, F. A metamorfose. Tradução de Modesto Carone. São Paulo: Comapanhia Digital, 2012.

KAFKA, F. Narrativas do espólio. Tradução de Modesto Carone. São Paulo: Companhia das Letras, 2012.

KAFKA, F. O desaparecido ou Amerika. Tradução de Susana Kampff Lages. São Paulo: 34, 2012 .

LÖWY, M. Franz Kafka: sonhador insubmisso. Tradução de Gabriel Cohn. Rio de Janeiro: Azougue Editorial, 2005.

OCTAVIO, P. O arco e a lira. Tradução de Paulina Wacht Ari Roitman. São Paulo: CosacNaify, 2012.

PLATÃO. A república. São Paulo: Martin Claret , 2011. 